\title{
Considerations in glaucoma therapy: fixed combinations versus their component medications
}

REVIEW

This article was published in the following Dove Press journal:

Clinical Ophthalmology

17 December 2009

Number of times this article has been viewed

\author{
Eve J Higginbotham \\ Morehouse School of Medicine, \\ Atlanta, GA, USA
}

Correspondence: Eve J Higginbotham Dean and Senior Vice President for Academic Affairs, Morehouse School of Medicine, 720 Westview Drive SW, Atlanta, GA, USA 303।0-1495

Tel + I 404-752-I 728

$\mathrm{Fax}+\mathrm{I}$ 404-752-1594

Email ejhigginbotham@msm.edu

\begin{abstract}
Fixed combinations of medications that lower intraocular pressure (IOP) are increasingly used in the treatment of glaucoma and ocular hypertension and offer several potential advantages over combined use of the separate component medications including enhanced convenience, improved adherence, reduced exposure to preservatives, and possible cost savings. This review aims to examine the current role of IOP-lowering fixed combinations in disease management. The results of studies that compared the efficacy and safety of IOP-lowering fixed combinations with their component medications are summarized, including those fixed combinations that consist of a prostaglandin analog and timolol. The fixed combinations currently available for use in the United States are fixed-combination dorzolamide/timolol (FCDT) and fixed-combination brimonidine/timolol (FCBT). Both of these fixed combinations reduce IOP more effectively than their component medications used separately as monotherapy. FCBT therapy also demonstrates a more favorable safety profile and reduced ocular allergy compared to monotherapy with brimonidine, a component medication. Few studies have directly compared the efficacy and safety of FCDT and FCBT, but available evidence suggests that FCBT is at least as effective as FCDT in lowering IOP and is more comfortable and better tolerated. Additional studies are needed to further evaluate the comparative efficacy and tolerability of FCDT and FCBT in the management of glaucoma and ocular hypertension.
\end{abstract}

Keywords: glaucoma, intraocular pressure, fixed combination, adherence, brimonidine

The goal of treatment in glaucoma and ocular hypertension is to reduce intraocular pressure (IOP) to a target pressure sufficiently low to prevent glaucomatous progression. The most commonly used classes of IOP-lowering medications are the prostaglandin analogs, beta-adrenergic receptor antagonists (beta-blockers), alpha adrenergic receptor agonists (alpha agonists), and carbonic anhydrase inhibitors (CAIs). For many patients, a single medication is insufficient to reduce IOP to the target pressure, and the treatment regimen includes 2, 3, or more medications from different classes.

In recent years the number and use of fixed combinations of IOP-lowering medications for treatment in glaucoma and ocular hypertension has grown substantially. These fixed combinations contain 2 medications in a single bottle and offer several advantages over concomitant use of the medications from separate bottles. Most important is the increase in patient convenience that results from the use of fewer bottles and eyedrops of medication and sometimes from dosing fewer times each day. The improved convenience of a regimen containing a fixed combination rather than 2 separate medications is likely to lead to better adherence. Although few, if any, studies have directly evaluated

submit your manuscript | www.dovepress.com 
adherence to IOP-lowering fixed combinations compared with the component medications used separately, there is evidence that adherence in glaucoma is better when regimens are simple rather than complex. ${ }^{1}$ A retrospective study using prescription data from a large national healthcare provider concluded that the rate of prescription refills was reduced when patients added a second prescription to their IOP-lowering regimen. ${ }^{2}$ In other disease states, studies have shown significantly better adherence with fixed combinations (1 pill) than with the separate components (2 pills). For example, in systemic hypertension, another chronic asymptomatic disease associated with low levels of long-term adherence to therapy, ${ }^{3}$ retrospective studies using pharmacy records showed that patients were more apt to refill a prescription for a fixed combination than 2 separate prescriptions for the component medications, ${ }^{4}$ and patients on a fixed combination had medication available for more days of therapy compared with patients on the separate component drugs. ${ }^{5}$

Because there is no possibility of a washout effect and no need to wait between instillation of the separate individual medications, both efficacy and adherence may be enhanced when a fixed combination is used rather than the separate component medications. Use of a fixed combination may also represent a safety improvement, because the patient's overall daily exposure to preservative may be decreased. Finally, there are potential cost savings associated with the use of fixed combinations, especially for patients with prescription insurance who have 1 copay for a fixed combination rather than 2 for separate medications. Moreover, in the United States, the availability of a generic fixed combination of dorzolamide and timolol increases access for those patients who previously could not afford this therapeutic option.

A disadvantage that should be highlighted is that it is not possible to change the drug concentration or dosing schedule for one component medication independently of the other when using a fixed combination. However, if adherence is improved by simplifying the regimen, the advantages of using a fixed combination outweigh this disadvantage.

\section{Historical overview of IOP-lowering fixed combinations}

Fixed combinations containing pilocarpine and another IOP-lowering medication have been used historically in the treatment of glaucoma. In the United States, however, epinephrine/pilocarpine (E-pilo ${ }^{\circledR}$; Ciba Vision) is not currently commercially available, timolol/pilocarpine (Timpilo ${ }^{\circledR}$; Merck \& Co., Inc.) never received United States Food and Drug Administration (FDA) approval, and betaxolol/pilocarpine (Betoptic Pilo ${ }^{\circledR}$; Alcon Laboratories, Inc.) was approved in 1997 but was never marketed. The primary reason that pilocarpine combinations are no longer commonly used is that the component drugs are not generally preferred therapy. Although newer preparations of pilocarpine have bypassed the need for frequent dosing of up to 4 times each day, the side-effect profile of pilocarpine (most commonly blurred vision and decreased night vision, less often eye irritation and headache) still limits its usefulness in glaucoma therapy. Epinephrine also often shows poor ocular tolerability. The selective beta-blocker betaxolol continues to be available. Although useful in selected patients with a history of pulmonary disease, this medication is not as effective in IOP lowering as nonselective beta-blockers such as timolol. ${ }^{6}$

The fixed combinations currently available for IOP lowering in the United States contain timolol and either the CAI dorzolamide or the alpha agonist brimonidine. Dorzolamide/timolol (Cosopt ${ }^{\circledR}$; Merck \& Co., Inc.) has been available since 1998 for reducing IOP in patients who do not respond adequately to beta-blockers alone, and it has become widely used and accepted. Brimonidine/timolol (Combigan ${ }^{\circledR}$; Allergan, Inc.) became available more recently in 2007 for reducing IOP in patients who require adjunctive or replacement therapy due to inadequately controlled IOP. Fixed combinations of a once-daily prostaglandin analog (latanoprost, bimatoprost, or travoprost) and timolol are available in many countries but are not yet approved for use in the United States. Studies related to the fixed combinations latanoprost/timolol, bimatoprost/timolol, and travaprost/timolol are included in this review because of their use in other countries.

\section{Efficacy and safety of fixed combinations compared with component medications}

The efficacy and safety of fixed combinations relative to their active components must be evaluated to obtain regulatory drug approval. For drug approval by the FDA, a fixed combination must have better efficacy than each of the component medications used as monotherapy. The fixed combination should also be as effective as the component medications given concomitantly in a 2-bottle regimen. The efficacy and safety findings from comparison studies of fixed combinations and their component medications ${ }^{7-13}$ are summarized in Table 1.

\section{Fixed-combination dorzolamide/timolol (Cosopt)}

Two separate 3-month, randomized, double-masked studies reported by Boyle et $\mathrm{al}^{7}$ and Clineschmidt et $\mathrm{al}^{8}$ compared 


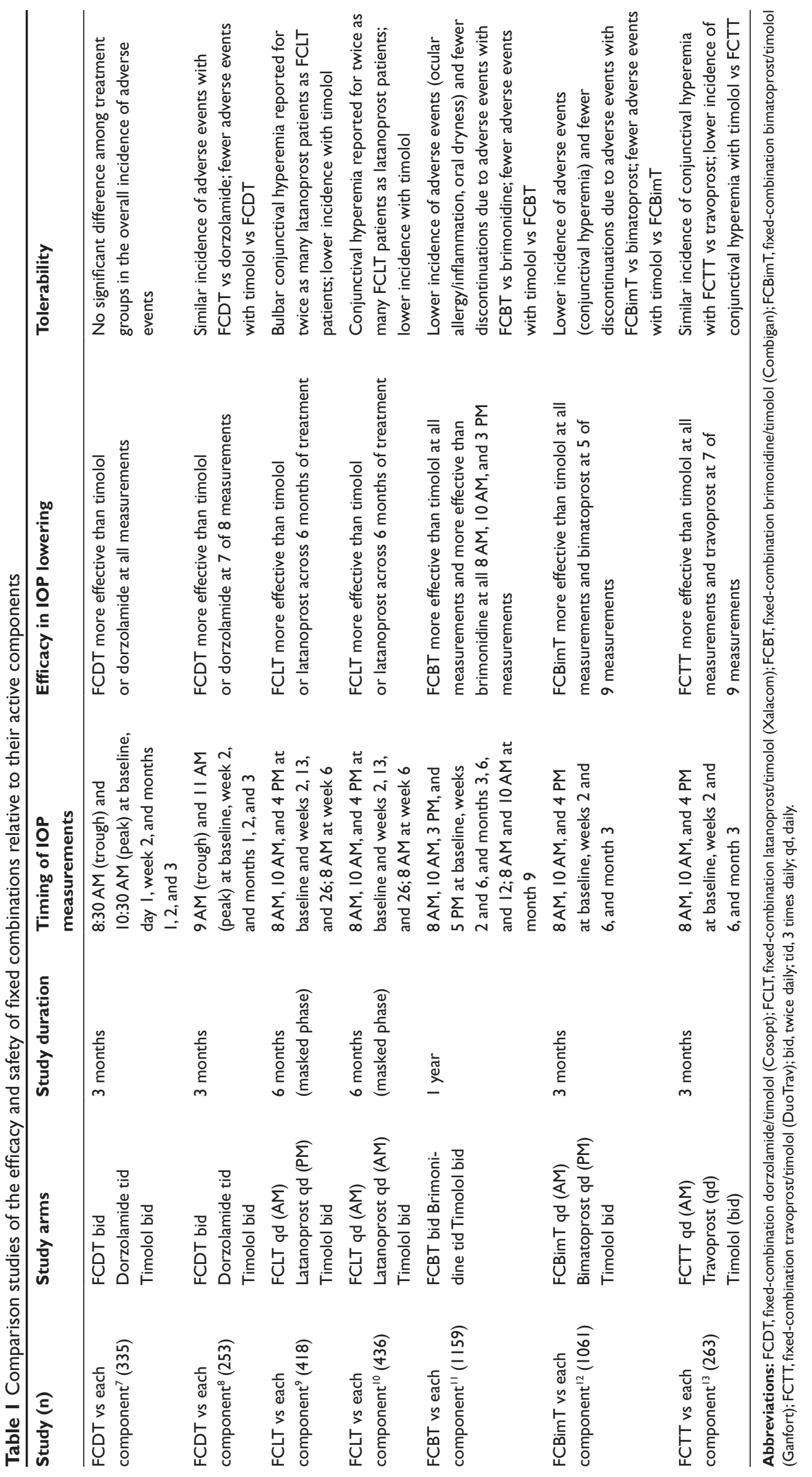


fixed-combination dorzolamide $2 \% /$ timolol $0.5 \%$ (FCDT) to monotherapy with the component medications. The Boyle study was carried out in 335 patients after washout of previous medications ${ }^{7}$ and the Clineschmidt study in 253 patients after a 3 -week run-in on timolol. ${ }^{8}$ FCDT and timolol were dosed twice daily while dorzolamide was dosed thrice daily. The results from both studies demonstrated that FCDT was more effective than either timolol or dorzolamide alone in reducing IOP at both peak and trough effect. The incidence of treatment-related adverse events was higher in the FCDT therapy group than in the timolol monotherapy group in the Clineschmidt study and similar between groups in the Boyle study. In each study, the overall incidence of treatment-related adverse events was similar with FCDT and dorzolamide monotherapy, and the incidence of the most common side effects (ocular burning/stinging and taste perversion) was also similar with FCDT and dorzolamide alone. ${ }^{7,8}$ Interestingly, in the Clineschmidt study, the incidence of conjunctivitis was significantly lower in the FCDT group than in the dorzolamide group ( $0 \%$ vs $6 \%, P=0.034) .{ }^{8}$ It should be noted that the concentration of the preservative is the same in FCDT and dorzolamide, although exposure to preservative was greater with dorzolamide because it was dosed 3-times daily (tid) vs twice daily (bid). Thus, the observation that conjunctivitis was less frequent with the former drug suggests that timolol may limit ocular inflammation or allergy when it is administered in a fixed combination.

Other studies have compared FCDT with a nonfixed combination of dorzolamide and timolol. In a 12-week, randomized, double-masked study reported by Hutzelmann et al ${ }^{14} 299$ patients run-in on timolol for 2 weeks were randomized to treatment with FCDT bid or concomitant dorzolamide bid and timolol bid. Based on the average of month 2 and month 3 data, FCDT and the nonfixed combination of dorzolamide and timolol were equivalent in IOP lowering, with the difference in mean IOP lowering between treatment groups $<0.1 \mathrm{mmHg}$ at both peak and trough effect. There was no significant difference between the treatment groups in the overall incidence of treatment-related adverse events, but eye pain was significantly less common in the FCDT group than in the concomitant therapy group ( $0 \%$ vs $4 \%, P=0.014)$, and on biomicroscopy corneal superficial punctate keratitis was also less common with FCDT than with concomitant timolol and dorzolamide ( $1 \% \mathrm{vs} 7 \%, P=0.005)$. In contrast, in a 3-month, randomized, double-masked study reported by Strohmaier et al $^{15}$ that compared FCDT bid with concomitant dorzolamide tid and timolol bid in 242 patients,
FCDT treatment was approximately $1 \mathrm{mmHg}$ less effective than concomitant therapy with dorzolamide and timolol in reducing IOP. The incidence of adverse events was similar between treatment groups, but eyelid pain or discomfort was significantly more frequent in the FCDT group than in the concomitant therapy group ( $6 \%$ of FCDT patients vs $1 \%$ of concomitant therapy patients, $P=0.036$ ).

Several open-label replacement studies have suggested that patients may achieve additional IOP lowering when they are switched from dorzolamide and a beta-blocker to FCDT. ${ }^{16-19}$ It should be noted that Phase IV trials such as these are subject to bias, because the investigators are not masked and the study design may influence the study outcomes. For example, in 2 of the studies ${ }^{16,17}$ patients were allowed to be on a selective beta-blocker before switching to FCDT, and in all 4 studies, there was a possibility of improved adherence after patients entered the study and switched to FCDT. Francis et $\mathrm{al}^{19}$ reported a randomized parallel-group study of FCDT and concomitant therapy as well as a study of FCDT replacement of concomitant therapy, and although the efficacy results favored FCDT in the replacement study, the randomized controlled trial demonstrated equivalent efficacy of FCDT and concomitant dorzolamide plus timolol therapy. Overall, the results of these studies suggest that FCDT and concomitant dorzolamide plus timolol therapy have similar efficacy in lowering IOP.

\section{Fixed-combination latanoprost/timolol (Xalacom)}

The first fixed combination of a prostaglandin analog and timolol to be developed was fixed-combination latanoprost $0.005 \% /$ timolol $0.5 \%$ (FCLT) (Xalacom ${ }^{\circledR}$; Pfizer, Inc.). To date, none of the fixed combinations of a prostaglandin analog and timolol have received FDA approval for use in the United States.

In a 6-month, randomized, double-masked study reported by Higginbotham et $\mathrm{al}^{9}$ of FCLT versus its component medications used as monotherapy, 418 patients run-in for 2 to 4 weeks on timolol bid were switched to FCLT once daily (qd) in the morning, latanoprost qd in the evening, or timolol bid. After 6 months, the mean change from baseline diurnal IOP was only approximately $1 \mathrm{mmHg}$ larger in the FCLT group than in the latanoprost group. Similar results were obtained in a second study of 436 patients that was reported by Pfeiffer, ${ }^{10}$ which was comparable in design to the Higginbotham study except that latanoprost monotherapy was dosed in the morning. FCLT reduced diurnal IOP by $1.2 \mathrm{mmHg}$ more than latanoprost monotherapy and $1.9 \mathrm{mmHg}$ 
more than timolol monotherapy. In both studies, FCLT lowered IOP substantially more than timolol alone. The differences in IOP lowering between FCLT and latanoprost alone were also statistically significant, but latanoprost monotherapy was nearly as effective as FCLT. More recently, a small, randomized, head-to-head study in 28 patients also showed only a small difference in efficacy $(<1 \mathrm{mmHg})$ between FCLT and latanoprost alone. ${ }^{20}$

No statistical analysis of adverse events was reported in these studies. Bulbar conjunctival hyperemia was reported for twice as many patients in the latanoprost group (18) as in the FCLT group (9) in the Higginbotham study, ${ }^{9}$ but conjunctival hyperemia was reported for twice as many FCLT patients (4) as latanoprost patients (2) in the Pfeiffer study. ${ }^{10}$ Therefore side effects do not appear to be reduced with FCLT compared with latanoprost monotherapy.

A randomized, double-masked, crossover study in 195 patients showed that FCLT qd in the morning does not lower IOP as effectively as concomitant treatment with latanoprost qd in the evening and timolol bid. ${ }^{21}$ However, a subsequent 12-week, randomized, double-masked, parallel-group study in 517 patients demonstrated that FCLT qd in the evening is as effective in lowering IOP as concomitant treatment with latanoprost qd in the evening and timolol bid. ${ }^{22}$

\section{Fixed-combination brimonidine/timolol (Combigan)}

A study reported by Sherwood et al ${ }^{11}$ compared fixedcombination brimonidine $2 \%$ /timolol $0.5 \%$ (FCBT) with its component medications used separately as monotherapy. In this 12-month, randomized, double-masked study, 1159 patients with glaucoma or ocular hypertension were washed out of any previous IOP-lowering medication and randomized to treatment with FCBT bid, brimonidine 2\% tid, or timolol $0.5 \%$ bid. Throughout 12 months of treatment, twice-daily FCBT was significantly more effective than either twice-daily timolol or thrice-daily brimonidine in reducing IOP. Mean IOP reductions from baseline were significantly greater with FCBT compared with timolol at all measurements $(P \leq 0.002)$ and compared with brimonidine at all measurements except those at $5 \mathrm{PM}$, after the afternoon dose of brimonidine monotherapy $(P<0.001)$. As might be expected due to the addition of a second drug, the fixed combination was less well tolerated than timolol monotherapy. Interestingly, however, FCBT demonstrated an improved safety profile compared with brimonidine monotherapy. There was a significantly lower incidence of treatment-related adverse events $(53.0 \%$ vs $62.8 \% ; P=0.006)$ and discontinuations for adverse events (14.3\% vs 30.4\%; $P<0.001)$ in patients treated with FCBT than in those treated with brimonidine alone. The rate of ocular allergy (allergic conjunctivitis) was $45 \%$ lower with FCBT than with brimonidine monotherapy $(P=0.020)$.

The reasons for the decrease in drug-related allergy in patients treated with FCBT compared with brimonidine alone are not fully understood. The decrease in allergy may have been due in part to decreased ocular exposure to brimonidine, since FCBT was dosed twice daily and brimonidine was dosed thrice daily as recommended in its prescribing information. However, in a study of 102 patients prospectively treated with twice-daily FCBT compared with a historical control group of 102 patients treated with twicedaily brimonidine monotherapy, the rate of ocular allergy was lower with FCBT than with brimonidine monotherapy even when both treatments were dosed twice daily. ${ }^{23}$

A study reported by Goni ${ }^{24}$ compared FCBT with a nonfixed combination of brimonidine and timolol. In this 12-week, randomized, double-masked study, 371 patients run-in on any monotherapy for at least 3 weeks were switched to treatment with FCBT bid or concomitant brimonidine bid and timolol bid. Throughout 12 weeks of treatment, FCBT and the nonfixed combination of brimonidine and timolol were equivalent in IOP lowering. Differences between treatment groups were $\leq 0.30 \mathrm{mmHg}$ for mean change from baseline IOP and $\leq 0.35 \mathrm{mmHg}$ for mean IOP, and none were statistically significant. For patients who were run-in on a beta-blocker, the switch to FCBT provided a mean additional IOP reduction of 4.4 to $5.7 \mathrm{mmHg}$. Both fixed and nonfixed brimonidine/timolol treatment were well tolerated, and there were no differences in adverse events between treatment groups.

\section{Fixed-combination bimatoprost/timolol (Ganfort)}

The prostaglandin analog bimatoprost has been combined with timolol in fixed-combination bimatoprost $0.03 \% /$ timolol $0.5 \%$ (FCBimT) (Ganfort $^{\circledR}$; Allergan, Inc.). In a 3-month, randomized, double-masked study reported by Brandt et $\mathrm{al}^{12}$ of FCBimT versus its component medications used as monotherapy, 1061 patients were treated with FCBimT qd in the morning, bimatoprost qd in the evening, or timolol bid. After 3 months, the mean change from baseline diurnal IOP in the FCBimT group ( $8.1 \mathrm{mmHg}$ ) was larger than in the timolol group (6.4 $\mathrm{mmHg}$ ) but not the bimatoprost group (7.9 mmHg). Although FCBimT was consistently more effective than timolol at reducing IOP, the mean reduction 
from baseline IOP was significantly larger with FCBimT than with bimatoprost alone at only 5 of 9 follow-up timepoints. However, FCBimT demonstrated improved tolerability compared with bimatoprost monotherapy. Both the overall incidence of treatment-related adverse events and the incidence of discontinuations due to adverse events were significantly reduced in the FCBimT group compared with the bimatoprost group. The most frequent side effect of treatment, conjunctival hyperemia, was reported for $22.7 \%$ of FCBimT patients compared with $38.5 \%$ of bimatoprost patients.

In a 3-week, randomized, double-masked, parallel-group study reported by Hommer et $\mathrm{al}^{25}$ FCBimT was compared with nonfixed bimatoprost and timolol or with bimatoprost alone in 445 patients. FCBimT qd in the morning reduced IOP as effectively as concomitant treatment with bimatoprost qd in the evening and timolol bid at the 3 follow-up timepoints in the study (hours 1, 2, and 8 at week 3 ). ${ }^{25}$ On biomicroscopy, the incidence of a clinically significant increase in conjunctival hyperemia was significantly lower with FCBimT $(8.5 \%)$ than with bimatoprost monotherapy (18.9\%) and numerically lower than with the nonfixed combination of bimatoprost and timolol (12.5\%).

\section{Fixed-combination travoprost/timolol (DuoTrav)}

The prostaglandin analog travoprost has been combined with timolol in fixed-combination travoprost $0.004 \% /$ timolol $0.5 \%$ (FCTT) (DuoTrav ${ }^{\circledR}$; Alcon Laboratories, Inc.). In a 3-month, randomized, double-masked study reported by Barnebey et $\mathrm{al}^{13}$ of FCTT versus its component medications used as monotherapy, 263 patients were treated with FCTT qd in the morning, travoprost qd in the evening, or timolol bid. FCTT reduced IOP substantially more than timolol alone throughout the study. At month 3, the mean reduction from baseline IOP was approximately 1.1 to $2.4 \mathrm{mmHg}$ larger in the FCTT group than in the travoprost group, but the difference was statistically significant at only 2 of 3 timepoints, and the reductions were measured from a baseline IOP that was approximately $0.6 \mathrm{mmHg}$ higher in the FCTT group. No statistical analysis of adverse events in the study was reported. The incidence of conjunctival hyperemia was $14.1 \%$ in the FCTT group, $11.6 \%$ in the travoprost group, and $1.1 \%$ in the timolol group.

Two studies have evaluated the efficacy and safety of FCTT qd in the morning compared with concomitant treatment with travoprost qd in the evening and timolol qd in the morning. ${ }^{26,27}$ In the study reported by Schuman et $\mathrm{al}^{26}$ the mean reduction from baseline IOP was greater with concomitant therapy than with FCTT by up to approximately $1.0 \mathrm{mmHg}$ at 5 of 9 follow-up timepoints and statistically similar between groups at the remaining timepoints. Similarly, in the study reported by Hughes et $\mathrm{al}^{27}$ mean IOPs were significantly lower in the concomitant therapy group than in the FCTT group by up to approximately $1.0 \mathrm{mmHg}$ at 4 of 9 timepoints during treatment. These results suggest that FCTT is slightly less effective than concomitant therapy with travoprost and timolol. The overall incidence of adverse events was similar between treatment groups in both studies, although in one study the incidence of conjunctival hyperemia was lower with FCTT (14.3\%) than with concomitant therapy $(23.4 \%){ }^{26}$

\section{Comparison of dorzolamide/timolol and brimonidine/timolol}

In a 2-month, open-label, surveillance study (CEED II) of fixed brimonidine/timolol use in 2133 patients at 123 centers in Canada, patients switched from FCDT monotherapy to FCBT monotherapy achieved average additional IOP lowering of 2.2 to $2.6 \mathrm{mmHg} .{ }^{28}$ As discussed previously, open-label drug replacement studies do not provide strong evidence of comparative drug efficacy, but the safety and tolerability findings of the study may be more informative. On a questionnaire given in the study, patients reported less burning, stinging, and metallic taste after switching from FCDT to FCBT, suggesting that fixed brimonidine/ timolol may be better tolerated than fixed dorzolamide/ timolol. ${ }^{28}$

In support of this suggestion, in a randomized, doublemasked, paired-eye study in 30 normal subjects, subject scores of ocular discomfort at 30 to 40 seconds after eyedrop instillation were significantly lower with fixed brimonidine/timolol than with fixed dorzolamide/timolol $(P<0.001) .{ }^{29}$ Although it is possible that the threshold for tolerating side effects is lower in normal subjects than in glaucoma patients with a potentially blinding eye disease, these results suggest that FCBT eyedrops are more comfortable than FCDT eyedrops upon instillation. ${ }^{29}$ The difference between the fixed combinations in ocular comfort may result from the difference in the $\mathrm{pH}$ of the formulations. Burning and stinging are commonly associated with use of acidic ophthalmic solutions, ${ }^{30,31}$ and FCDT is formulated at a $\mathrm{pH}$ of approximately 5.65. In contrast, the $\mathrm{pH}$ of FCBT ranges from 6.5 to 7.3 during its shelf life. The neutral $\mathrm{pH}$ of the fixed brimonidine/timolol formulation is likely to account for its better tolerability. 
The comparative efficacy and tolerability of FCDT and FCBT has not been well studied in head-to-head trials. In a randomized, investigator-masked, crossover study comparing FCDT and FCBT in 30 patients, there were no statistically significant differences in efficacy after 4 weeks of treatment. ${ }^{32}$ The study was underpowered to detect a $\leq 2 \mathrm{mmHg}$ difference in efficacy between the fixed combinations. ${ }^{32}$ Nonetheless, the similarity in the mean diurnal IOP reductions provided by the fixed combinations $(7.4 \mathrm{mmHg}$ for FCDT and 7.8 mmHg for FCBT) suggest that FCDT and FCBT had similar efficacy in reducing IOP. Ocular stinging/burning was significantly more common with fixed dorzolamide/timolol (9 patients) than with fixed brimonidine/timolol (1 patient, $P=0.027)$. In a randomized parallel-group comparison study, after 3 months of treatment the mean IOP was lower (15.6 vs $17.2 \mathrm{mmHg}, P=0.040$ ) and the mean reduction from baseline IOP was greater ( 7.7 vs $6.7 \mathrm{mmHg}, P=0.040)$ in patients treated with FCBT monotherapy than in patients treated with FCDT monotherapy. ${ }^{33}$ On a comfort/tolerability questionnaire, patients treated with fixed brimonidine/timolol reported significantly less stinging $(P<0.001)$, burning $(P=0.015)$, and unusual taste $(P=0.005)$ compared with patients treated with fixed dorzolamide/timolol.

Overall, the results of the clinical studies that have been published suggest that fixed brimonidine/timolol provides similar or greater IOP lowering compared with fixed dorzolamide/timolol and also demonstrates better ocular tolerability upon instillation. The greater comfort of fixed brimonidine/timolol eyedrops might lead to better adherence to treatment. Moreover, fixed brimonidine/timolol has a better safety profile than brimonidine monotherapy. The lower rate of ocular allergy associated with fixed brimonidine/timolol compared with brimonidine alone is clinically significant, because chronic use of brimonidine is sometimes limited by the occurrence of ocular allergy. These favorable safety and efficacy findings suggest that fixed brimonidine/timolol may have an important role in glaucoma management. Additional studies are needed to further evaluate the relative efficacy and tolerability of fixed brimonidine/timolol and fixed dorzolamide/timolol in lowering IOP as well as patient adherence and persistence with treatment.

Monotherapy remains the preferred initial choice of treatment in glaucoma; these fixed combinations should generally be used only when monotherapy has not provided low enough IOP. Both fixed dorzolamide/timolol and fixed brimonidine/timolol effectively reduce IOP when used alone ${ }^{7,8,11}$ or adjunctively with a prostaglandin analog,,$^{28,34}$ the most common first-line therapy. ${ }^{35}$ Further, both fixed dorzolamide/timolol ${ }^{7,8}$ and fixed brimonidine/timolol ${ }^{11}$ reduce IOP more effectively than monotherapy with their component medications.

\section{Comment}

The use of fixed combinations is preferred over separate use of both components primarily to facilitate adherence and persistence with treatment. Adherence is an important concern in glaucoma because up to $80 \%$ of patients may not take their medication as prescribed. ${ }^{1}$ One of the primary reasons for nonadherence in glaucoma is the inconvenience associated with eyedrop instillation. ${ }^{36}$ It is more convenient (both easier and faster) to instill 1 drop of a fixed combination than 2 drops from separate bottles of the component medications. Moreover, results of a recent study have suggested that a substantial proportion of patients on multiple drops (22\%) wait less than 3 minutes after taking an IOP-lowering medication before instilling a second medication. ${ }^{37}$ For those patients, a washout effect may occur, but no washout effect is possible when only 1 drop is given rather than 2 . Finally, for some patients cost is also a significant factor reducing adherence with prescription medications ${ }^{38}$ The average wholesale price (AWP) of medications changes over time, and based on the AWP, the cost of a fixed combination is not necessarily less than the cost of buying the components separately. ${ }^{39,40}$ However, for patients with prescription insurance and copays, the cost of a fixed combination is likely to be less than the combined cost of the component medications, reducing one possible barrier to compliance with treatment. The availability of a generic for FCDT is a potential advantage of use of this fixed combination, as it may further reduce the potential for cost to be a barrier to compliance.

A fixed combination should contain drugs that are safe and effective and that work well in combination with each other. The lack of availability of fixed combinations containing pilocarpine in the United States can probably be explained by the poor tolerability profile of pilocarpine. In contrast, fixed combinations of the prostaglandin analogs and timolol have not been approved for use in the United States. Based on the studies submitted to the FDA related to timolol/latanoprost, it is not clear that the improvement in efficacy with the prostaglandin analog/timolol fixed combinations relative to prostaglandin analog monotherapy is clinically significant. However, given the approval of these fixed combinations in other countries, it may be that subsets of patients are responsive to this therapy. Furthermore, the convenience of having 2 medications in 1 bottle cannot be underestimated. 
In summary, fixed combinations are important adjuncts to the armamentarium of available glaucoma therapies and offer critical options for patients who require more than one medication to control intraocular pressure.

\section{Acknowledgment}

Kate Ivins, $\mathrm{PhD}$, provided freelance medical writing assistance.

\section{Disclosures}

The author declares no proprietary interests in the medications discussed in this review. The author is a consultant for Alcon, Allergan, and Pfizer and has received speaker fees and grant support from each of these companies. Allergan provided funds for a medical writer to assist in the preparation of this review. The author had complete and sole control over the content of the review.

\section{References}

1. Olthoff CM, Schouten JS, van de Borne BW, Webers CA. Noncompliance with ocular hypotensive treatment in patients with glaucoma or ocular hypertension an evidence-based review. Ophthalmology. 2005;112(6):953-961.

2. Robin AL, Covert D. Does adjunctive glaucoma therapy affect adherence to the initial primary therapy? Ophthalmology. 2005;112(5): 863-868.

3. Van Wijk BL, Klungel OH, Heerdink ER, de Boer A. Rate and determinants of 10-year persistence with antihypertensive drugs. J Hypertens. 2005;23(11):2101-2107.

4. Dezii CM. A retrospective study of persistence with single-pill combination therapy vs concurrent two-pill therapy in patients with hypertension. Manag Care. 2000;9(9 Suppl):2-6.

5. Taylor AA, Shoheiber O. Adherence to antihypertensive therapy with fixed-dose amlodipine besylate/benazepril $\mathrm{HCl}$ versus comparable component-based therapy. Congest Heart Fail. 2003;9(6):324-332.

6. Strahlman E, Tipping R, Vogel R. A double-masked, randomized 1 -year study comparing dorzolamide (Trusopt), timolol, and betaxolol. International Dorzolamide Study Group. Arch Ophthalmol. 1995;113(8):1009-1016.

7. Boyle JE, Ghosh K, Gieser DK, Adamsons IA. A randomized trial comparing the dorzolamide-timolol combination given twice daily to monotherapy with timolol and dorzolamide. Dorzolamide-Timolol Study Group. Ophthalmology. 1998;105(10):1945-1951.

8. Clineschmidt CM, Williams RD, Snyder E, Adamsons IA. A randomized trial in patients inadequately controlled with timolol alone comparing the dorzolamide-timolol combination to monotherapy with timolol or dorzolamide. Dorzolamide-Timolol Combination Study Group. Ophthalmology. 1998;105(10):1952-1959.

9. Higginbotham EJ, Feldman R, Stiles M, Dubiner H; Fixed Combination Investigative Group. Latanoprost and timolol combination therapy vs monotherapy: one-year randomized trial. Arch Ophthalmol. 2002;120(7):915-922.

10. Pfeiffer N; European Latanoprost Fixed Combination Study Group. A comparison of the fixed combination of latanoprost and timolol with its individual components. Graefes Arch Clin Exp Ophthalmol. 2002;240(11):893-899.

11. Sherwood MB, Craven ER, Chou C, et al. Twice-daily $0.2 \%$ brimonidine$0.5 \%$ timolol fixed-combination therapy vs monotherapy with timolol or brimonidine in patients with glaucoma or ocular hypertension: a 12-month randomized trial. Arch Ophthalmol. 2006;124(9):1230-1238.
12. Brandt JD, Cantor LB, Katz LJ, Batoosingh AL, Chou C, Bossowska I; Ganfort Investigators Group II. Bimatoprost/timolol fixed combination: a 3-month double-masked, randomized parallel comparison to its individual components in patients with glaucoma or ocular hypertension. J Glaucoma. 2008;17(3):211-216.

13. Barnebey HS, Orengo-Nania S, Flowers BE, et al. The safety and efficacy of travoprost $0.004 \% /$ timolol $0.5 \%$ fixed combination ophthalmic solution. Am J Ophthalmol. 2005;140(1):1-7.

14. Hutzelmann J, Owens S, Shedden A, Adamsons I, Vargas E; Comparison of the safety and efficacy of the fixed combination of dorzolamide/timolol and the concomitant administration of dorzolamide and timolol: a clinical equivalence study. International Clinical Equivalence Study Group. Br J Ophthalmol. 1998;82(11):1249-1253.

15. Strohmaier K, Snyder E, DuBiner H, Adamsons I. The efficacy and safety of the dorzolamide-timolol combination versus the concomitant administration of its components. Dorzolamide-Timolol Study Group. Ophthalmology. 1998;105(10):1936-1944.

16. Choudri S, Wand M, Shields MB. A comparison of dorzolamidetimolol combination versus the concomitant drugs. Am J Ophthalmol. 2000;130(6):832-833.

17. Martone J, Mead A. Combination treatment may improve efficacy. Rev Ophthalmol. 2001;8(September):82-84.

18. Bacharach J, Delgado MF, Iwach AG. Comparison of the efficacy of the fixed-combination timolol/dorzolamide versus concomitant administration of timolol and dorzolamide. J Ocul Pharmacol Ther. 2003;19(2):93-96.

19. Francis BA, Du LT, Berke S, Ehrenhaus M, Minckler DS; Cosopt Study Group. Comparing the fixed combination dorzolamide-timolol (Cosopt) to concomitant administration of $2 \%$ dorzolamide (Trusopt) and $0.5 \%$ timolol - a randomized controlled trial and a replacement study. J Clin Pharm Ther. 2004;29(4):375-380.

20. Magacho L, Reis R, Shetty RK, Santos LC, Avila MP. Efficacy of latanoprost or fixed-combination latanoprost-timolol in patients switched from a combination of timolol and a nonprostaglandin medication. Ophthalmology. 2006;113(3):442-445.

21. Diestelhorst M, Larsson LI; European Latanoprost Fixed Combination Study Group. A 12 week study comparing the fixed combination of latanoprost and timolol with the concomitant use of the individual components in patients with open angle glaucoma and ocular hypertension. Br J Ophthalmol. 2004;88(2):199-203.

22. Diestelhorst M, Larsson LI; European-Canadian Latanoprost Fixed Combination Study Group. A 12-week, randomized, double-masked, multicenter study of the fixed combination of latanoprost and timolol in the evening versus the individual components. Ophthalmology. 2006;113(1):70-76.

23. Motolko MA. Comparison of allergy rates in glaucoma patients receiving brimonidine $0.2 \%$ monotherapy versus fixed-combination brimonidine $0.2 \%$-timolol $0.5 \%$ therapy. Curr Med Res Opin. 2008;24(9):2663-2667.

24. Goni FJ; Brimonidine/Timolol Fixed Combination Study Group. 12-week study comparing the fixed combination of brimonidine and timolol with concomitant use of the individual components in patients with glaucoma and ocular hypertension. Eur J Ophthalmol. 2005;15(5):581-590.

25. Hommer A; Ganfort Investigators Group I. A double-masked, randomized, parallel comparison of a fixed combination of bimatoprost $0.03 \%$ / timolol $0.5 \%$ with non-fixed combination use in patients with glaucoma or ocular hypertension. Eur J Ophthalmol. 2007;17(1):53-62.

26. Schuman JS, Katz GJ, Lewis RA, et al. Efficacy and safety of a fixed combination of travoprost $0.004 \% /$ timolol $0.5 \%$ ophthalmic solution once daily for open-angle glaucoma or ocular hypertension. Am J Ophthalmol. 2005;140(2):242-250.

27. Hughes BA, Bacharach J, Craven ER, et al. A three-month, multicenter, double-masked study of the safety and efficacy of travoprost $0.004 \% /$ timolol $0.5 \%$ ophthalmic solution compared to travoprost $0.004 \%$ ophthalmic solution and timolol $0.5 \%$ dosed concomitantly in subjects with open angle glaucoma or ocular hypertension. J Glaucoma. 2005;14(5):392-399. 
28. Ahmed I. CEED II: an in-depth look at the latest findings. Clin Surg $J$ Ophthalmol. 2007;25(1):1-5.

29. Chan K, Testa M, McCluskey P. Ocular comfort of combination glaucoma therapies: brimonidine $0.2 \% /$ timolol $0.5 \%$ compared with dorzolamide 2\%/timolol 0.5\%. J Ocul Pharmacol Ther. 2007;23(4):372-376.

30. Shafi T, Koay P. Randomised prospective masked study comparing patient comfort following the instillation of topical proxymetacaine and amethocaine. Br J Ophthalmol. 1998;82(11):1285-1287.

31. Silver LH. Ocular comfort of brinzolamide $1.0 \%$ ophthalmic suspension compared with dorzolamide $2.0 \%$ ophthalmic solution: results from two multicenter comfort studies. Brinzolamide Comfort Study Group. Surv Ophthalmol. 2000;44 Suppl 2:S141-S145.

32. Arcieri ES, Arcieri RS, Pereira AC, Andreo EG, Finotti IG, Sá Filho WF. Comparing the fixed combination brimonidine-timolol versus fixed combination dorzolamide-timolol in patients with elevated intraocular pressure. Curr Med Res Opin. 2007;23(4):683-689.

33. Nixon DR, Yan DB, Chartrand JP, Piemontesi RL, Simonyi S, Hollander DA. Three-month, randomized, parallel-group comparison of brimonidine-timolol versus dorzolamide-timolol fixed-combination therapy. Curr Med Res Opin. 2009;25(7):1645-1653.
34. Lesk MR, Koulis T, Sampalis F, Sampalis JS, Bastien NR. Effectiveness and safety of dorzolamide-timolol alone or combined with latanoprost in open-angle glaucoma or ocular hypertension. Ann Pharmacother. 2008;42(4):498-504.

35. McKee HD, Gupta MS, Ahad MA, Saldaña M, Innes JR. First-choice treatment preferences for primary open-angle glaucoma in the United Kingdom. Eye. 2005;19(8):923-924.

36. Patel SC, Spaeth GL. Compliance in patients prescribed eyedrops for glaucoma. Ophthalmic Surg. 1995;26(3):233-236.

37. Sleath B, Robin AL, Covert D, Byrd JE, Tudor G, Svarstad B. Patientreported behavior and problems in using glaucoma medications. Ophthalmology. 2006;113(3):431-436.

38. Gellad WF, Haas JS, Safran DG. Race/ethnicity and nonadherence to prescription medications among seniors: results of a national study. J Gen Intern Med. 2007;22(11):1572-1578.

39. Fiscella RG, Green A, Patuszynski DH, Wilensky J. Medical therapy cost considerations for glaucoma. Am J Ophthalmol. 2003;136(1):18-25.

40. Rylander NR, Vold SD. Cost analysis of glaucoma medications. Am J Ophthalmol. 2008;145(1):106-113.
Clinical Ophthalmology

\section{Publish your work in this journal}

Clinical Ophthalmology is an international, peer-reviewed journal covering all subspecialties within ophthalmology. Key topics include: Optometry; Visual science; Pharmacology and drug therapy in eye diseases; Basic Sciences; Primary and Secondary eye care; Patien Safety and Quality of Care Improvements. This journal is indexed on

Submit your manuscript here: http://www.dovepress.com/clinical-ophthalmology-journal

\section{Dovepress}

PubMed Central and CAS, and is the official journal of The Society of Clinical Ophthalmology (SCO). The manuscript management system is completely online and includes a very quick and fair peer-review system, which is all easy to use. Visit http://www.dovepress.com/ testimonials.php to read real quotes from published authors. 